\title{
Documenting and Analyzing the Dying Cahuilla Language of Southern California
}

\author{
Berthold Riese *
}

\begin{abstract}
Cahuilla is a dying Indian language in Southern California, USA. It is actually not used in everyday conservation but remembered by some elderly people only. Since the 1960s it has been recorded and analyzed by several German scholars. This paper presents the history of research, major methods employed in its study and the current progress as well as remaining topics to be studied.
\end{abstract}

Keywords: dying language, Indian language, Cahuilla

\section{Personal background}

For the last three years, I have resumed a former research interest in the American Indian language called Cahuilla. This was possible due to a research grant from the German Research Council (Deutsche Forschungsgemeinschaft). My initial interest originated during a year of research spent at the Getty Center for the History of Art and the Humanities in Santa Monica, California, ${ }^{(1)}$ in 1986-87 and was furthered through field and archival research and language courses taught during the years 1991 and 1994. Since 2005 I have been assisted by linguist Dr. Ingo Mamet. Our project headquarters is the former Institute of Cultural Anthropology at the University of Bonn, Germany, now part of the Department of Romance Languages.

\section{The languages of California}

California is one of the regions of the world with the most diverse languages. It thus compares to the Caucasus region in Eurasia and to Eastern Bolivia in South America. One reason for the language diversity in California is geographical and chronological. California was one of the first regions in the Americas to have been settled by immigrants, coming to America well over 10,000 years ago passing from Siberia to Alaska on a broad stretch of land then existing between both continents. From there they might have followed

\footnotetext{
* Berthold Riese: Department of Romance Languages, Institute for Ethnology and American Studies, University of Bonn, Oxfordstr. 15, 53111 Bonn, Germany. E-mail: briese@ uni-bonn.de.

(1) The Center has since moved to Brentwood, a suburb of Los Angeles.
} 
the Pacific coastline to the south. Some of these immigrants settled from time to time near the coast, and explored the coastal mountain ranges, where each group occupied an isolated territory protected by rugged hills and mountains, and in this isolation developed each their own languages. The underlying argument, that human settlements in mountainous regions tend to develop great language diversity, holds equally well for explaining the diversity of languages in Eastern Bolivia, the Caucasus and several other regions of the world.

Many of the California Indian languages represent two language stocks, not represented elsewhere in the Americas: The Penutian and the Hokan stocks. ${ }^{1}$ Besides these "indigenous languages", later intrusions originating in the east can be observed, namely a minor influx of languages from the Algonkian stock (Yurok) intruded into Central and Northern California, and a major group, constituted by languages of the Uto-Aztecan stock, comprising some 30 languages intruded into southern California. With these the Cahuilla language is affiliated, as shown in the diagram. ${ }^{2}$ The intrusions into California by Uto-Aztecan languages was slow and probably fairly late in time, since genetically related languages of this intruding group are still close neighbours in California and neighbouring regions to the east and south. That is to say, the slow and steady dispersal of Uto-Aztecan populations had not yet been disrupted at the advent of Europeans 300 years ago.

The Cahuilla language itself is internally differentiated into three dialects, the Desert, Pass and Mountain dialects. These dialects are named from the environment in which their speakers formerly lived: The Pass Cahuilla, living in the broad, not very highly elevated pass between the San Bernardino and San Jacinto Mountains centering on the modern city of Banning; the Mountain Cahuilla, living in higher elevated parts of the San Jacinto and Santa Rosa Mountains and the Desert Cahuilla occupying the vast valley floor, extending from the San Gorgonio Pass to the Salton Sea.

\footnotetext{
(1) In this characterization I am following the lead of Marianne Mithun and Lyle Campbell (1979). Other linguists posit that most Californian languages have cognates elsewhere. The most extreme position in this respect has been promoted by the late Joseph Greenberg (1987), who includes them all in his Amerindian language stock.

(2) Other Uto-aztecan languages, namely Pomo and Tübatulabal intruded further to the north into Central California.
} 


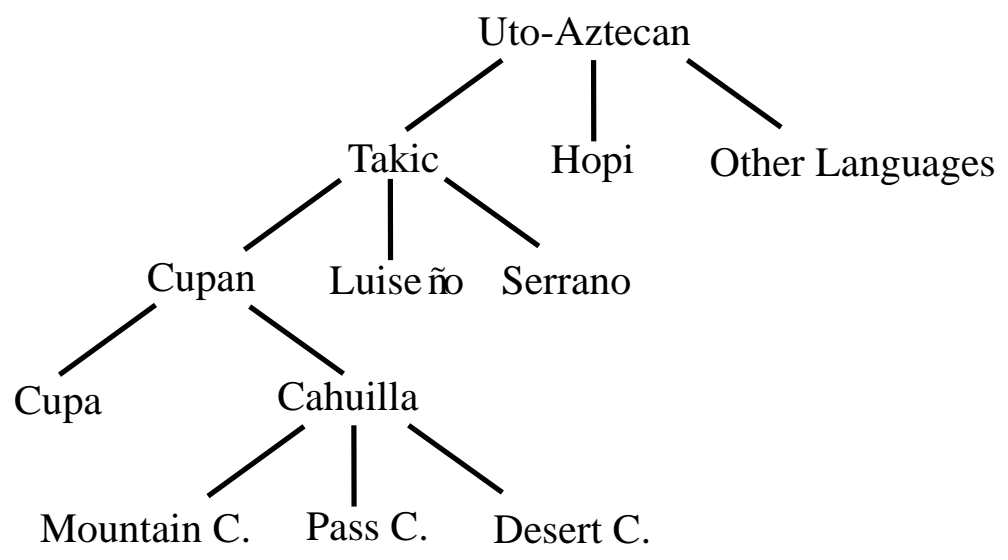

\section{The origin of the name Cahuilla}

In contrast to other Indian groups of Southern California, e.g. Diegueño, Gabrieliño and Luiseño, who have received their names from the nearest Catholic Mission, the origin of the name Cahuilla is unknown. Although Hansjakob Seiler, the foremost expert for this language, considered a group internal origin possible, this seems implausible since the word as used in the Cahuilla language itself is kaaviya, which possesses a stress pattern that betrays its foreign origin. The written form of the name with its $l l$ strongly suggests more specifically a Spanish origin.

\section{Cahuilla as a dying language}

For over 50 years there have been no active speakers of the Cahuilla language. The population is too small and individuals are too well integrated into the Anglo-American world as to feel urged to use their former tongue in everyday communication. Persons who still have remembrances of hearing and speaking it are now well over 70 years of age. They remember "their" language having been used by elders and to a lesser degree by themselves when they were in their infancy and youth. While in the 1960s a few elderly persons could still recount stories and personal recollections in Cahuilla fluently, now all that remains is approximately a dozen who have a fairly good passive knowledge. ${ }^{1}$

\section{Project goals}

\footnotetext{
(1) Among these our informants, Sat Torres, his niece Hazel Duro, Katherine Siva Saubel, Alvino Saubel, and Annie Hunter.
} 


\section{Documenting and Analyzing the Dying Cahuilla Language of Southern California}

This moribund state of the Cahuilla language convinced us that our aim of documenting and analyzing this dying language should focus on the enlargement of the corpus of available texts from older sources, since new elicitations would not produce coherent and useful texts. Modern Cahuilla Indians would be of help in understanding these older texts and perhaps also in restricted linguistic elicitation inquiries but they could not be our primary source of new language data. Elicitation however has been a quite fruitful method in the 1960, when Seiler made ample use of it; and it has proven a rewarding research method in other dying languages as well. ${ }^{(1)}$ This gave us the hope that this method might produce good results; and Mamet has indeed used this approach with several informants during our project.

By size, the most rewarding corpus of older Cahuilla texts are texts and notes recorded by John Peabody Harrington [1884-1961] during the years from 1920 to 1950 and revised with informants perhaps also a few years beyond. Harrington was a long-time linguist with the Bureau of American Ethnology of the Smithsonian Institution of Washington, which is a U.S.-government agency for all matters concerning the indigenous populations of the Americas, their culture and languages. He had a solid linguistic background studying first at the University of California and later at the universities of Leipzig and Berlin. ${ }^{2}$ He was, however, not interested in methodological or theoretical issues but in the documentation of spoken language. In this domain he was excellent, due to his acute hearing of phonetic performance and his very good grasp of morphology. He was also indefatigable in recording other California Indian languages, among which the group of Chumash languages, the now totally extinct language of the north-westerly neighbours of the Cahuilla, received his most intensive consideration over the years. ${ }^{3}$ Although his Cahuilla data are not as extensive as his Chumash documentation, they amount to some 25 narrative texts of indigenous make up. All his notes, even coherent narrations by his informants are written down on small paper slips. They have been microfilmed in a very orderly fashion and made accessible on microfilm almost twenty years ago, at which time I discovered them in the holdings of the Southwest Museum in Pasadena, California.

Second in quantity but first in quality is the corpus of texts assembled by Hansjakob Seiler, later Professor of linguistics at the University of Cologne (Germany) and his

\footnotetext{
(1) Frauke Sachse has recently used this procedure with good results in her unpublished study of the moribund Xinca language in Southern Guatemala.

(2) The latter were then, at the beginning of the $20^{\text {th }}$ century the leading institutions in linguistic theory. Witness Karl Bühler among others. Berlin was the world leading center for non-European language. It is possible but not documented that Harrington learned Nahuatl (Aztec) in Berlin with Eduard Seler, then the foremost authority in this Uto-Aztecan language.

(3) See Mamet (2005).
} 


\section{Berthold Riese}

assistants Anna Fuchs and Kiojiro Hioki. Their fieldwork and data analysis with the help of native speakers was accomplished during the decade of 1955-1964. This research was also sponsored largely by the German Research Council. As a major result of their efforts they published a volume of 20 texts (Seiler 1970), a grammar (Seiler 1977) and a dictionary (Hioki \& Seiler 1979). They thus produced one of the most useful, comprehensive and systematic studies of any Native American language. ${ }^{(1)}$

Cahuilla, although a dying language, has thus been well documented just before vanishing. Our contribution will therefore not consist in documenting its actual agony but rather in broadening of the published documentation and contributing new in depth analysis. Others may add to this the description of the process of decay and perhaps even the artificial revival which is actually underway. ${ }^{2}$

\section{Linguistic analysis}

Our linguistic analysis of the Cahuilla language focuses on phonology, morphology and the lexicon. It continues studies by Seiler's group, and will improve them and will expand their scope, by delving further into Harrington's data. The limitations of the analysis of our predecessors was due not so much to analytical defects but rather to a structural deficiency of their research: Seiler's major language informants were members of a close knit group of the Desert Cahuilla. And his three main informants were even members of one nuclear family: Chona Dominguez, her husband Joe Lomas and their daughter Alice López. Thus the complete range of speech possibilities of the language is not represented in Seiler's corpus, rather one dialect and one sub-dialect represented by one family. Since most stories collected by Seiler from these informants have probably been told and retold internally in this family it is to be assumed that stylistics, lexicon and other features are very homogeneous, not representing the language as a whole. Adding Harrington's data to this corpus will effectively counteract these limitations in broadening the range of speakers, dialects (Mountain Cahuilla) and idiolects. ${ }^{3}$

Some phonological phenomena not correctly analysed by Seiler are immediately evident confronting his classifications with Harrington's data and re-analysing them: $l l$ and $l$ are not two distinct phonemes as assumed by Seiler but positional or free allophones of one

\footnotetext{
(1) Other similarly comprehensive studies originate with Ekkehard Malotki on the Hopi language (also Uto-Aztecan), Robert M. Laughlin on the Tzotzil Maya language of Chiapas (Mexico) and Christian Cornelis Uhlenbeck on the Blackfoot language of Canada.

(2) A course in "Spoken" Cahuilla by Katherine Siva Saubel and Pamela Munro, is a first step in this direction. We have not checked if and to what extent this teaching material has been used in reviving and spreading the language.

(3) As yet we have been only partially successful in identifying Harrington's informants and their dialect affiliation.
} 
phoneme. The same holds true for $c h$ and $s h$. This part of our research is largely Mamet's task, who will also re-analyse the stress pattern and morphology as proposed by Seiler's group. Additionally there will be some historical comparative research into Uto-Aztecan languages based on the Takic languages Cahuilla, Cupeño and Luiseño, all three formerly spoken in Southern California.

I myself have concentrated my efforts on the lexical phenomenon of loan-words, intending to explain their historic origin and their uneven distribution in general semantic fields. In comparison for example with Japanese or even German it is astonishing to see how few loan-words have been adopted at least in narrative Cahuilla texts, recounted not later than 1970, that focus on traditional Indian culture and belief. Most loan-words to be found in Harrington's and Seiler's collection of texts have a clear Spanish origin. These are easily detected, since Spanish has several phonemes not represented in Cahuilla, e.g. $r$, and Cahuilla has a different stress pattern for words, stressing the first stem-syllable, whereas Spanish distributes the stress on the ultimate or penultimate syllables. Adding to this, in many cases, the clear phonetic and semantic commonalities between the Cahuilla and Spanish words lead to an almost certain analysis. However, some uncertain cases remain, especially since not all word pairs are recognizable and contrastive. Up to now I have identified close to 50 loan words in an overall corpus of 2000 lexemes; and I hope to add another 50 in future research. Half of these loan-words pertain to the cattle complex, that is to say, to animals, material equipment und tasks involving cattle raising. ${ }^{(1)}$ One reason why loanwords are concentrated in this semantic domain is clear at hand: Pre-Spanish Cahuilla Indians did not know cattle and did not raise animals. Thus the complex of cattle raising was utterly foreign to them. However, their contact with Spanish missionaries coming from Mexico during the $18^{\text {th }}$ century brought them into contact with this strange economic system, and being open-minded, they readily adopted some new words along with the knowledge of their cultural significance. Loan words from English, which constitutes the foremost foreign contact language for over 150 years by now, are astonishingly sparse and appear only with a considerable time lag. I do not have a ready explanation for this, especially if you consider the case of the word denoting 'school'. The Cahuilla adopted the Spanish word escuela (Cahuilla eskwéela) not the English word school into their language, although they have known schools only during Anglo-American an dominance, not during the preceding Spanish period. One hypothesis could be that, locally, English was not immediately established as the lingua franca when California gained independence from Mexico and joined the United States, and that instead a local Spanish patois prevailed far

\footnotetext{
(1) Most common are ach/ash 'horse' or 'mule'?, chikóoti 'rope', káarne 'meat', kaváayo 'horse', kwéro 'cow hide', váaka 'cow', vekéeru 'cowboy'.
} 


\section{Berthold Riese}

into the $20^{\text {th }}$ century in rural Southern California. But this hypothesis needs much more research to be verified scientifically.

\section{Literary and anthropological analysis}

Texts are not only the primary basis of our linguistic analysis but also constitute a form of utterance to be investigated on their own merits. This is my second research field in our joint project. The variation of textual genres is not great. Formal discourse, jokes, riddles and many other genres are completely lacking from the textual corpus available. All texts are narrative, containing embedded dialogues and songs from time to time. Nonetheless these narratives amount to the sizable corpus of over 50 texts, and even more, if we accept rumours about further unpublished texts existing in writing or on speech recording devices. They are worth analysing with respect to rhetoric, ethnographic content, comparative literature and theoretical issues of psychological nature.

One of the more striking rhetoric means employed in almost all texts, and much discussed in other Amerindian language studies, are overt quotation markers. ${ }^{\mathbb{1}}$ I have this far discovered three: yal, wam and miyaxwen. Yal is the most common. It is an abbreviated verb and often appears syncopated as the verbal suffix /-1/. Wam, morphologically simple and of uncertain etymology, is very rare $;^{2}$ and miyaxwen, a full-fledged depersonalized verb, seems to be restricted to the Mountain Cahuilla dialect or even narrower to Harrington's informant Adán Castillo. The textual distribution, syntactic position and exact meaning of these quotatives will have to be investigated further.

Our corpus of texts also offers some interesting ethnographic information. Some of it invites speculation about their cultural-historical persistence from prehistoric Uto-Aztecan times to now, (i.e., since they are documented among both the Cahuilla and the Aztec), which form two extremes of the genetic tree of this language stock. Thus Cahuilla and Aztec people have surely not been in contact for centuries, and similar concepts encountered in both must be part of an ancient common tradition. The concept of the Sacred Bundle is one case. This concept is widely distributed among non-sedentary Indians of North America, vanishing rapidly as one travels south and practically non-existent among sedentary groups of Mesoamerica. However it is present among the Aztecs in Central Mexico and among the Cahuilla, distant some 2000 kilometers to the north. This might witness the preservation of a very ancient concept in Aztec culture reminiscent of their former cultural condition as a hunting and gathering tribe roaming the Sonoran desert far to the North of their later home-land. The tradition of a cultural hero whose heart turns

\footnotetext{
(1) E.g. in Quechua by Sabine Dedenbach-Salazar Sáenz, a former member of my Institute.

(2) Cf. Text 1: 14 and Text 3: 2d.
} 
into a flower after sacrifice might be another case in fact. Cahuilla mythology attaches this episode to the culture hero Takush, the Aztecs to Quetzalcoatl.

As to comparative literature, a most interesting theme is the wer-bear. Since the bear is the mightiest animal in California and as such entered into the official flag of the state, it is not astonishing that Cahuilla Indians should attach ambivalent feelings to it: Sometimes the bear is amicable in its intent towards men, sometimes he is a dangerous enemy. Among the Cahuilla Indians the belief was widespread that this animal can change its physical appearance into a man and vice versa. Naxanish hunwet, as the wer-bear is called in Cahuilla, can appear as a normal man and might be misjudged in his intentions and physical force, and thus might be the origin of calamities to whoever happens to deal with him. This concept compares with similar creatures called "Werwolf" in Europe and "Nahualli" in Mesoamerica and to a lesser degree with the folkloric and literary concept of the vampire. In the culture of the Cahuilla Indians it is part of a broad belief in the possibility of humans, animals and plants to change physical appearance.

As a contribution to the theory of myth and narrative I will investigate some of our Cahuilla texts pertaining to certain ontogenetically conditioned types of folktales according to theories developed by Vladimir Propp in his "Morphology of the Folktale" (English translation 1958) and expanded by Norbert Bischof in his book "Im Kraftfeld der Mythen" (1996). I will not, however, delve into a structural analysis à la Claude Levi-Strauss, since his approach seems too simple and unproductive, and it has been adequately presented by Levi-Strauss himself in his 7 volume "Mythologiques" (1964-1993), although Cahuilla stories are not treated by him, since he did not know them at the time of conceiving and writing his mythological oeuvre.

\section{Is revitalization of the Cahuilla language possible and feasible?}

The Cahuilla language was never spoken by many people. Estimates of the population high, shortly before intensive and permanent contacts with Europeans at about 1800, do not exceed some 2000 speakers living simultaneously in a vast territory of about $700 \mathrm{~km}^{2}$. Nonetheless, it is a completely developed language comprising part of the world's cultural heritage. Its preservation therefore seems a must.

However, there is no speaking community left. Since Indians tracing their descent to former Cahuilla speakers live dispersed over Southern California and mostly not on reservations, there is also no regional community in existence in which such a language revival would make social sense and would be mentally accepted by prospective pupils. Equally negative is the economic aspect of such a revival. What advantage would it bring to a young "Cahuilla" to learn his ancestors' language in school, a language in which he will not be able to communicate with anybody except with his teacher? It would be much 


\section{Berthold Riese}

more productive for him to learn Spanish or Chinese or Korean, since these are languages spoken by sizable and economically active population segments in California. With such language competencies, not with Cahuilla, he would have a social and economic advantage over Southern Californians who are monolingual speakers of English or Spanish.

In spite of this situation, the revitalization of former Indian cultures and languages is a politically important goal in the United States and California. Therefore, government funds can be diverted into activities having such revitalization as their ultimate goal. The funding will however not last for long and will essentially be an unproductive investment. Perhaps a Museum will be built (which has been accomplished on the Cahuilla Morongo Reservation a long time ago and in Palm Springs, both on a very modest scale); books might be published, which will find no public readers but be appreciated by a few scholars (also accomplished for the Cahuilla); promotion measures might put a few activists for some time on the payroll of a "Tribal Institution" of some kind created for this purpose. ${ }^{(1)}$ Folklore, represented in festivals, handicraft and similar events might also be considered a path for revitalization. But on the whole, for Indians in the United States, other activities have shown to be economically much more productive; running a casino and developing tourism on their reservations are the two economically rewarding activities firmly established among North American Indians, the Cahuilla being no exception. As of 2009, four casinos are operating on three Cahuilla reservations; and at least two canyons have been opened to tourists for individual hiking trips and guided tours. But these activities do not rely on language skills other than English.

My proposal is this: Since the Cahuilla language is incurably moribund, we should concentrate on publishing and analysing what has been preserved by such activists as Harrington and Seiler. By this means even as a dead language Cahuilla can be appreciated in the future by whoever wishes to do so, unimpeded by political correctness, ideological prescription, or short term interests.

\section{References}

Bischof, Norbert. 1996. Das Kraftfeld der Mythen. München: Piper.

Greenberg, Joseph H. 1987. Language in the Americas. Stanford: Stanford University Press.

Laughlin, Robert M. 1975. The Great Tzotzil Dictionary of San Lorenzo Zinacantán. Washington, D.C.: Smithsonian Institution.

Lévi-Strauss, Claude. 1964-1993. Mythologiques I-VII. Paris.

Mamet, Ingo. 2005. Das Ventureño Chumash. Bern.

Mamet Ingo. 2008. Man-Bear travels to Hel (=Languages of the World/ Text Collections, 27). München:

\footnotetext{
(1) This kind of self-serving institution seems to have been established recently among the Cahuilla Indians. Persons on the pay roll (?) are in part foreigners (that is to say, not being members of traditional Cahuilla families) who foster a revitalization program for selfish economic goals (own income) and not primarily with an altruistic general cultural intent.
} 
Documenting and Analyzing the Dying Cahuilla Language of Southern California

Lincom Europe.

Mithun, Marianne \& Lyle Campbvell. 1979. The Languages of Native America. Austin: University of Texas Press.

Propp, Vladímir. 1958. Morphology of the Folktale. Austin \& London: University of Texas Press

Saubel, Katherine Siva \& Pamela Munro. 1982. Chem 'ivillu': Let's speak Cahuilla. Los Angeles and Banning, CA: UCLA American Indian Studies Center and Malki Museum Press.

Seiler, Hansjakob. 1970. Cahuilla Texts with an Introduction. (= Language Science Monographs, 6). Bloomington: Indiana University \& Den Haag: Mouton \& Co.

Seiler, Hansjakob. 1977. Cahuilla Grammar. Banning: Malki Museum

Seiler, Hansjakob \& Kiojiro Hioki. 1979. Cahuilla Dictionary. Banning: Malki Museum

Uhlenbeck, Christian Cornelis. 1930-1934. English-Blackfoot and Blackfoot-English Dictionary. Amsterdam.

Uhlenbeck, Christian Cornelis. 1938. A Concise Blackfoot Grammar. Amsterdam. 